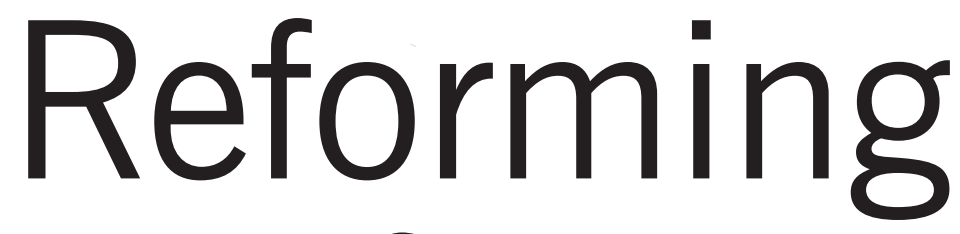

Welfare
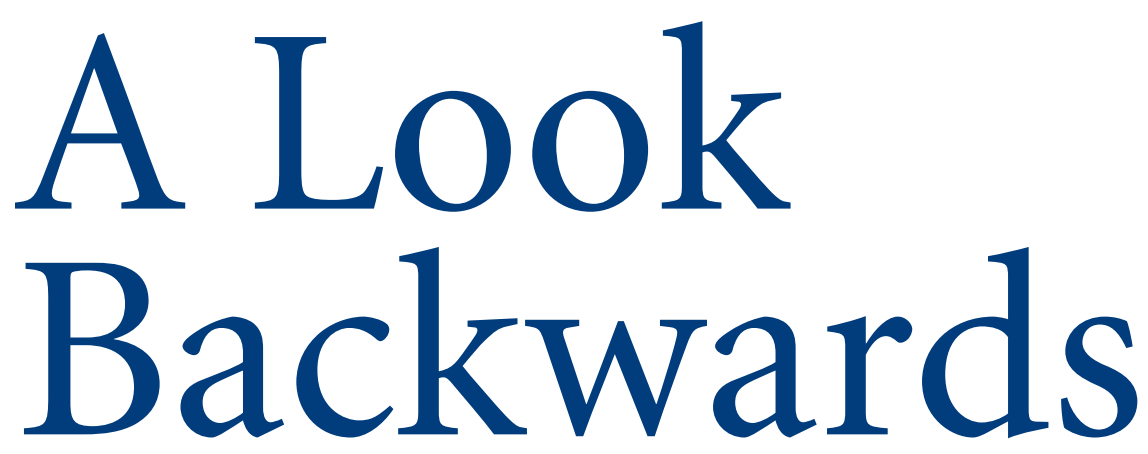

Introduction

In its final report the Welfare Working Group (WWG)

asserts that 'Our welfare system has major deficiencies that need to be corrected if we are to achieve the outcomes New Zealanders expect from the welfare system. Addressing these issues requires innovation and fundamental change to the welfare system, rather than further piecemeal change' (WWG, 2011, p.i). The report fails to meet all these aims because of: (1) its imprecision and lack of clarity about key terminology; (2) the agenda which it set, including the terms of reference under which it worked; and (3) the assumptions it made about the purpose and role of income support

Michael O'Brien is an Associate Professor at Massey University in the Social Work and Social Policy Programme, and also teaches in the School of Counselling, Human Services and Social Work at the University of Auckland. systems and the values on which those systems should be based. Furthermore, if implemented, its fundamental approach, directions and recommendations create pathways for welfare in New Zealand which are destructive and divisive and do not deliver the 'better social and economic outcomes for people on welfare, their families and the wider community' (ibid.), which it claims to be the goal. This article pursues these issues and concludes that the WWG has failed in its fundamental role of providing good quality policy advice. 


\section{Agenda, terms of reference, definitions}

As Humpty Dumpty once said, the best place to start is at the beginning. 'The beginning' for discussion of the WWG's report must be the terms of reference. The significance of those terms of reference for this discussion lies in two considerations. First, the terms of reference defined 'the problem' in a particular way, namely as a problem of 'welfare dependence'. Second, the terms of reference quite specifically excluded critical issues from the working group's consideration. Specifically, the group was unable to include the crucial the work of Deacon in relation to values and ideas in the context of social policy, with the following apposite quotation from his work: 'welfare raises fundamental questions about the rights and obligations of citizenship, and about the scope and purpose of public policy, which is essentially about our responsibilities one for another' (McClelland and Smyth, 2006, pp.21-2). As they, and a range of policy commentators and analysts, have observed, policy analysis is not value free and the discussion of values and ideologies needs to be informed and

\section{... the framing of the 'problem' as one of 'dependence' is based on the political and ideological assumption that 'the problem' is the behaviour of beneficiaries.}

issues of superannuation, the tax/benefit interface and in particular Working for Families and benefit rates in its work. The exclusion of these dimensions of welfare policy meant that the working group was unable to provide a thorough, comprehensive and considered report on income support and social security. It might be argued that the working group cannot be criticised for an inadequate report on the basis of items that were not included in the terms of reference. However, members of the group knew that these issues were outside the scope of their attention when they agreed to join; thus, in accepting the terms of reference they also accepted the parameters and definition of 'the problem' as defined by government in creating the WWG. Moreover, as I will discuss later in this article, they did, implicitly and to some degree explicitly, take up the issue of benefit levels.

Why do the terms of reference matter? In their discussion of social policy and social policy analysis, McClelland and Smyth (2006, p.20) note that 'social policy is about purposeful activity to improve societal well-being ... [and] is particularly concerned with the distribution of wellbeing and social relationships. Social policy involves rational analysis and action but also political contest about different values and the position of different groups'. They go on to draw on supported by a thorough, thoughtful and coherent analysis of the requisite and appropriate data (Craig, Burchardt and Gordon, 2008; Esping-Andersen, 2002; George and Wilding, 1994; Hudson and Lowe, 2004; Lavalette and Pratt, 2006). The values which inform the work of the WWG are clear. Although not always explicitly articulated, they are in many respects reflected in the group's definitions and principles set out at the beginning of their final report; I will return to that below. In the context of thinking about issues of values in a social policy framework, it is worth noting Bradshaw's final comment in his recent reflection on Peter Townsend's contribution to poverty research when he noted that Townsend 'wanted to change the world. Let us try to do the same' (Bradshaw, 2010, p.vi). The WWG is clearly arguing for change in the way in which welfare is provided, organised and delivered, but in doing so comprehensively fails to explore the fundamental question asked by Richard Titmuss: namely, in whose interest is the change taking place? (Titmuss, 1968). Good social policy analysis and decision making will advance the interests, wellbeing and circumstances of the poorest and most vulnerable and in doing so must contribute to greater social cohesion and a better society. The WWG report fails on all these grounds.
The acceptance of 'welfare dependence' as the description and definition of 'the problem' is significant because it constructs and creates the discussion of social security, income support, government activity and beneficiary lives and behaviour in a particular kind of way. That is, 'the problem' becomes one of beneficiary receipt of social welfare assistance (defined as dependence), an approach which leads to the focus being placed on the lives, behaviours and circumstances of beneficiaries rather than on the adequacy of benefit levels, the cause of the poverty experienced by so many beneficiaries and their dependent children. Furthermore, such an approach also neglects consideration of other vital social and economic factors, such as the availability and quality of jobs, a key component of the New Zealand approach to income support (O'Brien, 2008). In the context of the discussion in this article, the significance of the 'problem definition' as one of 'dependence' is that policy advice, analysis and recommendations become framed by that definition and lead then to particular sets of recommendations and to neglect of key dimensions of the topic under consideration.

In its report, the WWG defines welfare dependence as benefit receipt for longer than six months (WWG, 2010, p.3). As the group's issues paper acknowledges, this is a completely arbitrary definition. 'Dependence' has been the subject of significant discussion in the social policy literature and clearly identified as a concept with multiple levels of meaning (see, for example, Dean and TaylorGooby, 1992; Gibson, 1995; Lister, 2004; O'Brien, 1997). However, as used by the WWG 'dependence' takes on a pejorative meaning, a use of the term which has become increasingly widespread in both the social security debates and, to a lesser extent, in other areas of social policy, such as services for families and for mental health users. That pejorative and ideological use strips the term of any descriptive usefulness and both shapes the discussion in particular ways and precludes meaningful and productive discussion of the nature, meaning and implications of 'being dependent'. It is an approach in which 'dependence' by definition is bad and must be stopped. What, then, of the 'dependence' of a 
newborn child on its parents' care and protection, or the 'dependence' of a frail, older person on his or her carers, or the 'dependence' of employers on having a skilled workforce or of employees on the availability of adequately paid work? 'Dependence' is a word with many meanings; defining it as the WWG has done fails to attend to these meanings and, even more importantly, shapes and determines the discussion in ways that are inimical to good social and economic outcomes.

As noted above, the framing of the 'problem' as one of 'dependence' is based on the political and ideological assumption that 'the problem' is the behaviour of beneficiaries. This framing then precludes and effectively disqualifies any discussion of the living standards, lives, circumstances and poverty levels experienced by beneficiaries, despite the extensive body of data which clearly demonstrates the levels of poverty among beneficiaries (see, for example, Centre for Social Research and Evaluation, 2007; Jensen et al., 2006; Krishnan, Jensen and Ballantyne, 2002; Perry, 2009; Stephens, 2003; Stephens, Frater and Waldegrave, 2000). Logically, but with significant and destructive consequences, the 'solution' then leads to an emphasis on changing that behaviour rather than on what is required to ensure that benefit levels are sufficient to at least minimise poverty (and ideally remove poverty), particularly the poverty experienced by children. Broad questions of income distribution, inequality and income adequacy do not need to be considered when the focus is placed on the behaviour of the beneficiaries rather than on the adequacy of their income. A focus on income adequacy and on preventing and reducing poverty would inevitably lead to much more fundamental and significant questions about the role of government and markets in distributing and redistributing income: that is a question which government, having established the WWG, could avoid by defining the problem as 'welfare dependence'. Unfortunately, and with disastrous consequences, as I will demonstrate below, the failure to attend to the question of poverty will mean the further entrenchment of poor living standards and of the severe and significant hardship

identified in the Living Standards research (Jensen et al., 2006).

Defining 'the problem' as resulting from the behaviour of beneficiaries also means that a fundamental component of the income support system was completely ignored. That is, the WWG completely failed to undertake any analysis of the nature of the job market, relying on assertions from employers that there were job vacancies which they had difficulty in filling (WWG, 2010,

\section{... the WWG completely failed to undertake any analysis of the nature of the job market, relying on assertions from employers that there were job vacancies which they had difficulty in filling (WWG, 2010, 2011).}

2011). In their discussion on this issue, the nature of those jobs and their match with the skills of beneficiaries is ignored. The final report does note that there are some current difficulties in the labour market (WWG, 2011, p.3), but places this to one side arguing that the task is to prepare beneficiaries so that they are able to compete in the job market when that improves. It is the state of the job market, and the economy - the demand (not supply) side of the equation - that is critical in moving people from benefits into work. Even more critical than its failure to attend to the nature of the labour market, however, is the WWG's lack of discussion of the implications of the available statistical data about the labour market. This data is conspicuous by its absence; for example, the most recent Household Labour Force survey (HLFS) shows a decline in part-time jobs (Statistics New Zealand, 2011), a key component of the labour market with particular significance and implications for lone parents and for those receiving a sickness or invalid's benefit. As the Alternative Welfare Working Group noted in its report, employment and jobs have been, historically, a key component of the New Zealand approach to social security and income support and are vital to any comprehensive and systematic analysis of welfare change and welfare directions (O’Brien et al., 2010). Any approach to issues of welfare change which does not consider what is happening in labour markets (the plural is deliberate) is both totally inadequate and certainly cannot be said to contribute in any way to improved social and economic outcomes for New Zealand and New Zealanders. Such work is certainly not good policy advice.

\section{The active citizen: reshaping and reducing welfare}

As much of the social policy literature in recent years has noted, one of the fundamental areas of debate and consideration in the reshaping and reforming of social security and income support is the relationship between rights and responsibilities, particularly as these relate to issues of the nature and form of contemporary citizenship. (For a useful discussion of many of the issues, see Dwyer, 2004). In its Marshallian conception, citizenship, in the context of welfare programmes, placed a strong emphasis on the rights of citizens in relation to their access to and use of a range of 'social goods'. As various commentators have demonstrated, international changes in welfare provision over the last two decades have emphasised responsibilities, with increasing constraints and sanctions being placed on and linked to the welfare rights of citizens (Andersen et al., 2005; Andersen and Jensen, 2005; Dwyer, 2000, 2004; Edwards and Glover, 2001; EspingAndersen, 2002; Hvinden and Johansson, 2007). While there are a range of influences and forces shaping this shift, one of the ways in which the shift is explored, described and captured is through the notion of what is often referred to as 
'active citizenship'. (For a useful discussion of aspects of active citizenship, see Andersen et al., 2005). Perhaps the most succinct definition of active citizenship is provided by Andersen et al.: 'a new ideal of citizenship or a new set of rights and duties based on a conception of a claimant (e.g. an unemployed person) as an active citizen. The active citizen is granted more autonomy and choice but in return is assumed to be self-responsible, flexible and mobile' (2005, p.vii). The 'active citizen' is often discussed and described in contrast to the 'passive citizen', depicted as the hallmark of 'old social security'. (For an example of this see Clark and Maharey, 2001.) However, as I have noted elsewhere, the characterisation of 'old social security' as 'passive' and its contrast with the in contemporary welfare systems, which have an emphasis on building social and community relationships in the interests of all citizens. However, it is a distinction that is reinforced by providing assistance to those in paid work while denying that assistance to beneficiaries and their children who rely on income support ( $\mathrm{St}$ John and Craig, 2004).

'Active citizenship', as undertaken by those who secure paid work, may reduce poverty levels, particularly for those children whose families are eligible for Working for Families tax credits. However, the WWG calculates that implementation of all its recommendations would, over ten years, reduce the numbers receiving a social security benefit by somewhere between 49,000 and 93,000 (WWG, 2011,

\section{The WWG's lack of clarity about the meaning of 'dependence' is reflected too in its discussion about the nature and purposes of the social security/income support system.}

new 'active social security' is a spurious distinction which ignores the form, nature, structure and history of social security (O'Brien and Salonen, 2011). In its final report the WWG reflects some of this language and shift, characterising the existing income support system as 'passive' in contrast with the 'activity' which, it argues, is at the heart of its proposals (see, for example, chapter 2 and the figure on p.57).

In the conclusion to their review of welfare policy changes, Andersen et al. (2005) suggest that the outcomes of the growth and development of 'active citizenship' are uncertain and unknown. However, in the context of the work of the WWG the outcomes are entirely predictable, particularly in relation to the reinforcement of distinctions between the deserving (those in paid work and receiving in work tax credits) and undeserving (those receiving a benefit) poor, and in relation to issues of child poverty. This distinction between the deserving and undeserving poor has its roots in the old Poor Law (Jones and Novak, 1999; Morris, 1994). It has no place p.161). (A further 8,00o are added to the calculation on the basis that they are supported by a beneficiary who secures paid work and therefore move from receiving a benefit). I want to leave aside the important assumptions built into this calculation and focus the discussion briefly on the implications of this anticipated effect in the context of 'active citizenship'.

On the basis of these calculations, somewhere between 250,000 and 300,000 would, on current numbers, still be reliant for their income on a social security benefit. Many of these would be sole parents with responsibilities for dependent children. At present, upwards of 170,000 children live in poverty (based on calculations in St John and Wynd, 2008). Depending on the mix of those who moved from a benefit into paid work, more than 100,000 children would remain in poverty after implementation of the changes. 'Active citizenship' with its emphasis on responsibilities and obligations means that these children and their parent/carer will remain in poverty, a poverty that will become even deeper as a result of the implementation of the report's recommendations. The individualised emphasis on 'responsibility' will result in a deterioration in the living standards and circumstances of too many children, a deterioration below what are already very poor and unacceptable living standards. The deterioration will occur because of the proposal to create a standard benefit and because of the proposals for tightening of third-tier assistance, assistance which is critical for many beneficiaries with children as they attempt to provide their children with opportunities and necessities available to others.

Significantly, although benefit rates were outside the WWG's terms of reference, the group's discussion of the standard benefit, set at the rate of the unemployment benefit (currently the lowest rate of income support), and their proposals around third-tier assistance represent at least an implicit definition of acceptable benefit levels, without any discussion of the implications in the light of the available evidence on living standards and poverty. (Incidentally, this suggestion of a standard benefit rate is not new; earlier reforms in 1990 and the work on the core benefit idea by the last Labour government represent but two of its previous iterations.) While the report's recommendations will exacerbate poverty levels, this is not discussed in the final document. Presumably it is not important. These outcomes certainly mean that 'active citizenship' does not represent an advance in terms of welfare; rather it will mean a fundamental retreat from policy development which would lead to improved social and economic outcomes, given the effects of poverty, especially on children. Clearly, McClelland and Smyth's argument and Bradshaw's challenge drawn on above, namely that good policy work should lead to improvements in human circumstances and conditions, are not met. On a range of grounds, then, the WWG report fails to meet fundamental imperatives for appropriate and effective social policy advice and decision making.

\section{The purposes of income support}

The WWG's lack of clarity about the meaning of 'dependence' is reflected too in its discussion about the nature and purposes of the social security/income 
support system. The issue of values is critical here. From the basis of a neoliberal and residual approach to welfare provision (George and Wilding, 1994), the report provides a set of terminological definitions and descriptions at the beginning in which it says that it refers to the current system as 'the benefit system' and their new proposal as 'the welfare system' (WWG, 2011, p.vii). However, it then proceeds, in a somewhat confusing way, to use other language such as 'safety net' and 'social assistance' in its discussion of the nature and purpose of the system. There is a disturbing lack of clarity, accuracy and consistency here; but, much more importantly, throughout their discussion there is an approach to welfare and the role of the state in welfare which can only be described as limited and coercive, reflecting the residual and neoliberal frames within which their work is located. Significantly, in their discussion of the principles on which their proposals are based (WWG, 2011, p.37), there is no reference to adequacy of income and prevention of poverty as aims of income support, ${ }^{1}$ fundamental omissions which speak voluminously of both their approach to the work and of the significance of the terms of reference in setting the agenda, as discussed earlier in this article: references to poverty in the final report are in the context of participation in paid work. Significantly, there are a number of references to budgeting assistance and financial management, including key elements of compulsion, all indicating a failure to address issues of poverty and income adequacy comprehensively.

This selectiveness of focus clearly demonstrates a failure to meet the WWG's own objective of providing an overhaul of welfare. The narrow focus on benefits and benefit incomes means that the dual and judgemental approach in current welfare provision is completely ignored and, arguably, reinforced. Beneficiaries are to be managed and controlled and their lives are to revolve around paid work; by contrast (the dual approach), if they move into a relationship and are entitled to state support and welfare assistance through tax credits, they are allowed to reduce their work participation because they will meet the work test requirements through their partner, as is reflected in the data from the recent evaluation of the Working for Families package (Ministry of Social Development and Department of Inland Revenue, 2010).

\section{Concluding comments}

On a number of counts the WWG's report on 'welfare dependency' both fails to meet its own objectives and, much more importantly, provides a framework for a major step backward to nineteenthcentury welfare provision. Informed by a neo-liberal approach to welfare, its narrow, inadequate and disturbingly selective terms of reference, its construction of the agenda and its failure to engage with key ideas and concepts and contemporary debates and data lead inevitably to a set of recommendations which can only mean that the 'active citizen' who sits at the centre of their approach to welfare is increasingly impoverished and undeserving. The recommendations represent the complete antithesis of aspirations to deliver 'better social and economic outcomes for people on welfare, their families and the wider community' (WWG, 2011, p.i). They will achieve the opposite.

\footnotetext{
Principle 2 in the report is: 'provision of financial support to people not in employment when no other income is available'. This does not include any reference to or discussion of adequacy (Welfare Working Group, 2011, p.37).
}

\section{References}

Andersen, J., M. Guillermard, P. Jensen, P.and B. Pfau-Effinger (eds) (2005) The Changing Face of Welfare, Bristol: The Policy Press

Andersen, J. and P. Jensen (eds) (2005) 'Active' Citizenship: the new face of welfare, Bristol: The Policy Press

Bradshaw, J. (2010) 'Reflections on Peter Townsend's contribution to social security research', in P. Saunders and R. Sainsbury (eds), Social Security, Poverty and Social Exclusion in Rich and Poorer Countries, Antwerpen: Intersentia

Centre for Social Research and Evaluation (2007) Pockets of Significant Hardship and Poverty, Wellington: Ministry of Social Development

Clark, H. and S. Maharey (2001) Pathways to Opportunity/Nga Ara Whai Oranga: from social welfare to social development, Wellington: Ministry of Social Development

Craig, G., T. Burchardt and D. Gordon (eds) (2008) Social Justice and Public Policy: seeking fairness in diverse societies, Bristol: The Policy Press

Dean, H. and P. Taylor-Gooby (1992) Dependency Culture, Hemel Hempstead: Harvester Wheatsheaf

Dwyer, P. (2000) Welfare Rights and Responsibilities: contesting social citizenship, Bristol: The Policy Press

Dwyer, P. (2004) Understanding Social Citizenship: themes and perspectives for policy and practice, Bristol: The Policy Press

Edwards, R. and J. Glover (eds) (2001) Risk and Citizenship: key issues in welfare, London: Routledge

Esping-Andersen, G. with D. Gallie, A. Hemerijck and J. Myles (2002) Why We Need a New Welfare State, Oxford: Oxford University Press

George, V. and P. Wilding (1994) Welfare and Ideology, Hemel Hempstead: Harvester Wheatsheaf
Gibson, D. (1995) 'Dependency: the career of a concept', in S. Graham (ed.), Dependency, the Life Course and Social Policy, Sydney: SPRC, University of New South Wales

Hudson, J. and S. Lowe (2004) Understanding the Policy Process: analysing welfare policy and practice, Bristol: The Policy Press

Hvinden, B. and H. Johansson (eds) (2007) Citizenship in Nordic Welfare States, Abingdon: Routledge

Jensen, J., V. Krishnan, V., R. Hodgson, S. Sathiyandra and R. Templeton (2006) New Zealand Living Standards 2004, Wellington: Ministry of Social Development

Jones, C. and T. Novak (1999) Poverty, Welfare and the Disciplinary State, London: Routledge

Krishnan, V., J. Jensen and S. Ballantyne (2002) New Zealand Living Standards 2000, Wellington: Ministry of Social Development

Lavalette, M. and A. Pratt (eds) (2006) Social Policy: theories, concepts and issues (3rd edn), London: Sage

Lister, R. (2004) Poverty, Cambridge: The Polity Press

McClelland, A. and P. Smyth (eds) (2006) Social Policy in Australia: understanding for action, Melbourne: Oxford University Press

Ministry of Social Development and Department of Inland Revenue (2010) Changing Families' Financial Support and Incentives for Working: the summary report of the evaluation of the Working for Families package, www.ird.govt.nz/aboutir/reports/research, accessed April 2011

Morris, L. (1994) Dangerous Classes, London: Routledge

O'Brien, M. (1997) 'Dependency: beliefs, assumptions, evidence', in M. O'Brien and C. Briar (eds), Beyond Poverty, Auckland: Auckland Unemployed Workers' Rights Centre 
O'Brien, M. (2008) 'Social security in a globalised New Zealand', in N. Lunt, M. O'Brien and R. Stephens (eds), New Zealand, New Welfare, Melbourne: Cengage

O'Brien, M., S. Bradford, P. Dalziel, M. Stephens, M. Walters and W. Wicks (2010) Welfare Justice for All, Wellington: Caritas Aotearoa New Zealand

O'Brien, M. and T. Salonen (2011) 'Child poverty and child rights meet active citizenship: a New Zealand and Sweden case study', Childhood, 18:2, pp. 211-216

Perry, B. (2009) Household Incomes in New Zealand: trends in indicators of inequality and hardship 1982 to 2008, Wellington: Ministry of Social Development

St John, S. and D. Craig (2004) Cut Price Kids: does the 2004 'Working for Families' budget work for children?, Auckland: Child Poverty Action Group

St John, S. and D. Wynd (eds) (2008) Left Behind: how social and income inequalities damage New Zealand children, Auckland: Child Poverty Action Group
Statistics New Zealand (2011) 'Household Labour Force Survey: December 2010 quarter', Hot Off The Press, retrieved 16 February 2011 from www.stats.govt.nz

Stephens, R. (2003) 'The level of financial assistance to families with dependent children: a comparative analysis', Social Policy Journal of New Zealand, 20, pp.173-96

Stephens, R., P. Frater and C. Waldegrave (2000) Below the Line: an analysis of income poverty in New Zealand, 1984-1998, Wellington: Graduate School of business and Government Management, Victoria University of Wellington

Titmuss, R. (1968) Commitment to Welfare, London: George Allen and Unwin

Welfare Working Group (2010) Long-Term Benefit Dependency: the issues, Wellington: Welfare Working Group

Welfare Working Group (2011) Reducing Long-Term Benefit Dependency: recommendations, Wellington: Welfare Working Group

\title{
Enhancing Performance-Based Regulation Lessons from New Zealand's building control system
}

Peter Mumford

Performance-based regulation establishes mandatory goals rather than enforcing prescriptive standards. Performance-based regulation has become popular over the past two decades as an alternative to prescriptive regulation, as it holds out the promise of simultaneously achieving health, safety, and environmental outcomes while facilitating innovation and reducing regulatory costs.

In the early 1990s New Zealand adopted a performancebased building control regime. This regime demonstrably failed, resulting in then 'leaky building' crisis. In Enhancing Performance-Based Regulation: Lessons from New Zealand's building control system Peter Mumford examines whether the failure can be attributed to the performance philosophy and features of the regime.

Mumford explores two strategies for resolving the challenges of decision making in a permissive performance-based regulatory environment: improving the predicative capability of decision-making systems through the better application of intuitive judgement associated with expertise and wisdom, and treating novel technologies as explicit experiments.

Peter Mumford works for the Ministry of Economic Development. He has a broad public policy background, ranging from small and medium-sized enterprises policy and technology policy to regulatory impact analysis and regulatory policy in areas as diverse as securities markets regulation, building controls and international regulatory coordination.

An Institute of Policy Studies publication by Peter Mumford

Publication Date: April 2011

Format B5 Paperback, pp 205

ISBN ISBN 978-1-877347-43-6 - IPS/PUB/171 Price - \$27.60

(including P\&P within New Zealand)

Place your order by email, phone, fax or mail to

Institute of Policy Studies, Victoria University of Wellington

Email ips@vuw.ac.nz Telephone +64 44635307 Fax +64 44637413

PO Box 600, Wellington, New Zealand

An invoice will be issued with your order

\section{Enhancing Performance-Based Regulation}

Lessons from New Zealand's building control system

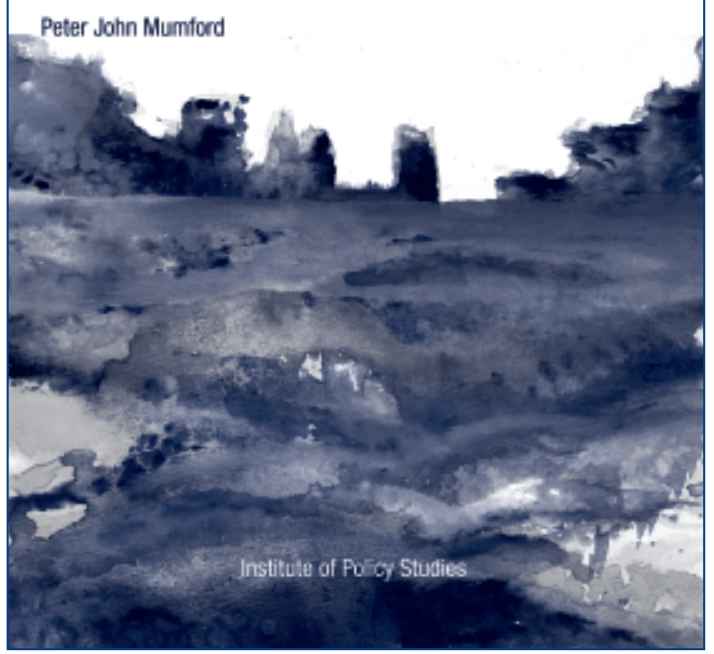

\begin{abstract}
renvironment: improving

(a)
\end{abstract}

